\title{
Effect of Gas-To-Liquid (GTL) fuels on marine diesel engines compared to F-76
}

\author{
R S Tol, BSc ${ }^{b *}$, Ir. Y Linden ${ }^{a}$
}

${ }^{a}$ Defence Materiel Organisation, The Netherlands; ${ }^{b}$ Netherlands Defence Academy, The Netherlands

*Corresponding author. Email: rs.tol@mindef.nl

\section{Synopsis}

With increasingly stringent emission regulations and evergrowing concern for the environment and human welfare, alternatives for distillate marine diesel oil are becoming more widely available. The Dutch department of Defence has committed itself to reduce the production of carbon dioxide due to burning fossil fuel by $70 \%$ in 2050 (compared to 2010). GTL is a liquid fuel produced from natural gas and manufacturers claim cleaner combustion. Measurements have been taken from a $360 \mathrm{~kW}$ Marine diesel engine over the engine envelope to compare the combustion performance of GTL against F-76, a NATO-standard DMA.

We found that combustion started earlier for GTL compared to F-76. The heat release rate, calculated using a single-zone combustion model, showed a more graduate heat release for GTL, resulting in a lower peak pressure and spatially averaged cylinder temperatures.

The engine's overall efficiency showed an increase of up to $0.5 \%$, while emissions of $N O_{X}$ reduced by more than $9 \%$. Despite the higher efficiency and GTL's $3.5 \%$ higher caloric value, the operating range of vessels is expected to decrease by $4 \%$ due to the $8 \%$ lower density of GTL.

Keywords: Marine fuels, GTL, F-76

\section{Authors' Biographies}

Lt Ruben Tol is a student at the Royal Netherlands Naval College. He obtained his bachelor's degree in 2018 on the topic of diesel engine combustion.

Lt Cdr Youri Linden is currently a marine engineer at Defence Materiel Organisation in Utrecht. He has previously been Deputy Marine Engineering Officer of HNLMS De Zeven Provincien. Earlier experience includes searider instructor CBRNDC/FF defence and in service support. 


\section{Introduction}

Improving the overall efficiency of ships and reduction of harmful emissions are topics widely investigated, e.g. [1] [9] [5]. The Dutch department of Defence has committed itself to reduce the production of carbon dioxide due to burning fossil fuel by $70 \%$ in 2050 (compared to 2010). Amongst (many) others, one topic of investigation is the use of alternative fuels to distillate marine diesel oils. Previous research has shown that Hydrotreated Vegetable Oils (HVO) can be a suitable alternative fuel. Bouwmeester found out that the reduction in carbon dioxide production can be reached by using $\mathrm{HVO}$ as an alternative to distillate marine diesel oil [2]. Not only because of the reduced carbon dioxide production, but also the vegetable origin of HVO makes it a more environmentally friendly fuel when evaluating the well-to-wheel principle.

The trend in commercial shipping to use gaseous fuels directly, and thereby meeting Tier III regulations without a flue gas after-treatment system, seems less attractive for naval vessels. Modification of existing operating units is costly if at all possible and carrying (liquefied) gas in potentially hostile environments is seen as an additional risk for current and future naval combatants. The logistics involved in operating worldwide using gaseous fuels is complex. Therefore, operating on liquid bio-based fuels, with the capability to switch back to fossil fuels when operationally required, provides an environmental advantage without compromising safety or complicating (wartime) logistics.

The GTL used for this research is produced by plants which use natural-gas based Fischer-Tropsch synthesis (FTS). FTS was discovered in the 1920s and was used by Germany in the Second World War to produce transportation fuels from coal. Recently biomass-based FTS has attracted more attention, since it can rely on mature technology developed for fossil feedstock [3].

The interest in Gas To Liquid (GTL) fuels is mainly driven by an effort to reduce harmful emissions. The design and operation of naval vessels sometimes requires personnel in positions where flue gas concentrations are (slightly) elevated. Harmful long- or short-term consequences for personnel are unacceptable. Interest in alternative fuels has also grown due to strict emission limits setup by the International Maritime Organisation for $\mathrm{NO}_{x}$ emissions. In addition, cleaner exhaust gases have operational advantages, such as a reduced signature. 17]

Reduction of emissions at the source i.e. at the combustion process provides the best solution. Measurements the RNLN performed on board a landing craft (LCVP) have shown a decrease in $\mathrm{NO}_{X}$ emission in the order of $10 \%$. This research, performed under more controlled conditions, aims at explaining the cause of this reduction.

\section{Methodology}

To study the difference between GTL and F-76 in marine diesel engines, experiments were performed on a four cylinder, turbo-charged diesel engine with a rated power of $360 \mathrm{~kW}$ at $1000 \mathrm{RPM}$. The main characteristics of the engine are presented in Table 1 . The load was applied by a controllable water brake. A total of seventeen different operating points through out the operating envelope of the engine are measured for both GTL and F-76. Due to technical difficulties with the test engine, measurements at 1000 RPM could not be performed. Therefore, the F-76 grid is limited to 950 RPM. The measurement grid is presented in Figure 1 .

Table 1: Engine data

\begin{tabular}{lcc}
\hline \hline name & value & unit \\
\hline Engine & MAN 4L20/27 & \\
Number of cylinders & 4 & {$[-]$} \\
Nominal Power & 360 & {$[\mathrm{~kW}]$} \\
Nominal Torque & 3438 & {$[\mathrm{Nm}]$} \\
Connecting rod & 0.52 & {$[\mathrm{~m}]$} \\
Bore & 0.20 & {$[\mathrm{~m}]$} \\
Stroke & 0.27 & {$[\mathrm{~m}]$} \\
Start of Injection & 4 & {$\left[{ }^{\circ} \mathrm{bTDC}\right]$} \\
Inlet valve Closes (IC) & 20 & {$\left[{ }^{\circ} \mathrm{aBDC}\right]$} \\
Exhaust valve Opens (EO) & 300 & {$\left[{ }^{\circ} \mathrm{aBDC}\right]$} \\
\hline
\end{tabular}




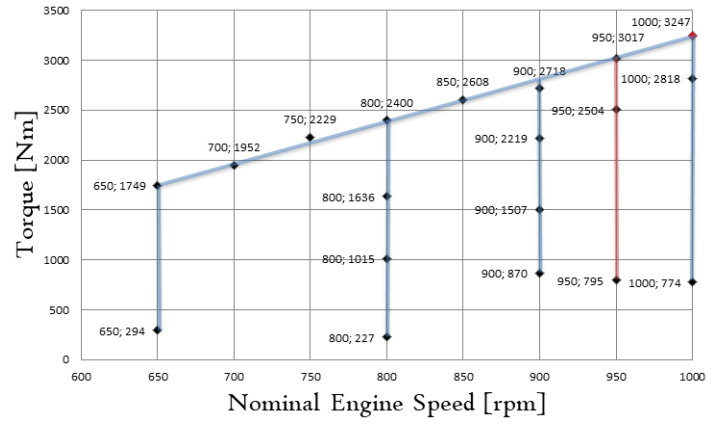

Figure 1: The measurement grid for GTL and F-76, the red line indicates the maximum nominal engine speed of F-76

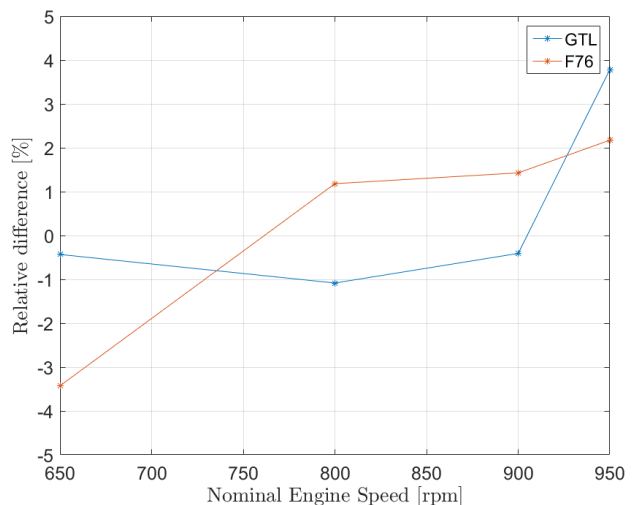

Figure 2: Relative difference between measured and calculated fuel flow

At each load point, after the engine has stabilised for ten minutes, data collection is started. Figure 4 gives an overview of the measurement setup and sensors. The pressure in all four cylinders is measured for 41 consecutive cycles, using a Kistler 7061B sensor in combination with the Kistler Ki-Box unit. Air flow to the engine is calculated from the pressure difference over an orifice. Fuel flow to the engine is measured by switching the feed and return line to a scale and timing the reduction of a set amount of mass of fuel from the scale. Emissions are recorded using the Horiba PG-350 connected to the M\&C PSP4000 with a heated feed line.

Since the combustion rate can not directly be measured, a single-zone model is used to derive it. The average pressure signal is used as an input for the single-zone combustion model. Only the closed part of the in-cylinder process is investigated from 'inlet valve closes' (IC) to 'exhaust valve opens' (EO). An overview of the relations within the model is presented in Figure 3 . The ideal gas law is used to calculate the change in in-cylinder temperature from the pressure, volume, mass and composition in the cylinder. Pressure serves as an input. Volume is calculated from the crank-angle. Mass is the combination of the trapped mass at IC and fuel injected. For the trapped condition a scavenge efficiency of $95 \%$ is assumed, leaving $5 \%$ residual gas in the cylinder. The mass in the cylinder at IC is based on the cylinder pressure and temperature. The cylinder temperature is calculated based on the inlet receiver temperature and heat pick-up during intake [11]. The composition in the cylinder is a combination of air and stoichiometric gas, based on the progress of combustion. The effect of liquid fuel in the cylinder is assumed to be negligible [6].

Verification of the model is done by comparing the measured and calculated fuel flow to the engine. The relative difference is well below $5 \%$, as can be seen in Figure 2. This can be atrributed to the simplicity of the single-zone model and some inaccuracies in the heat loss model. For this study, the accuracy obtained with this relative simple model is sufficient. Improvement can be obtained by slightly adjusting the parameters within the Woshni heat loss model. However, for this study the values proposed by Ding are used. 


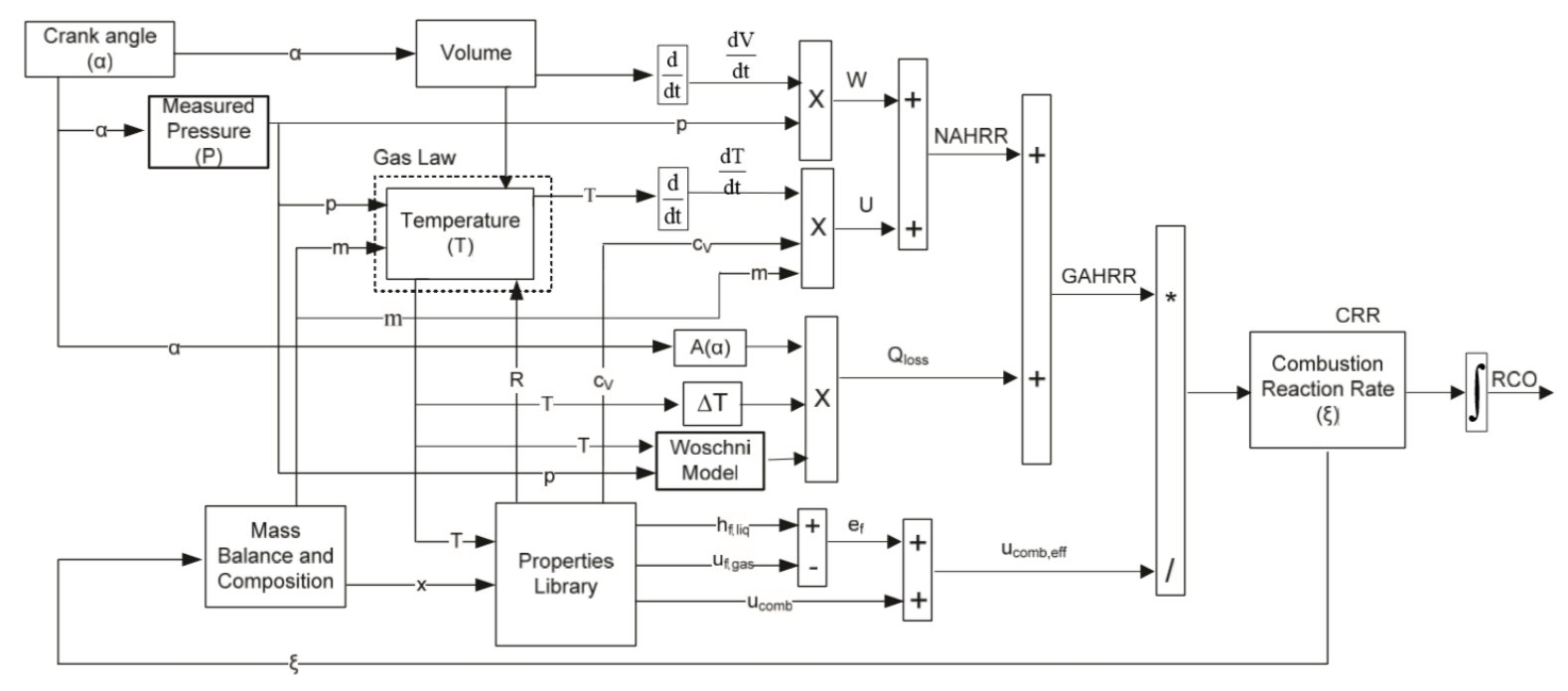

Figure 3: Overview of relations within the single-zone model, from Ding [4]

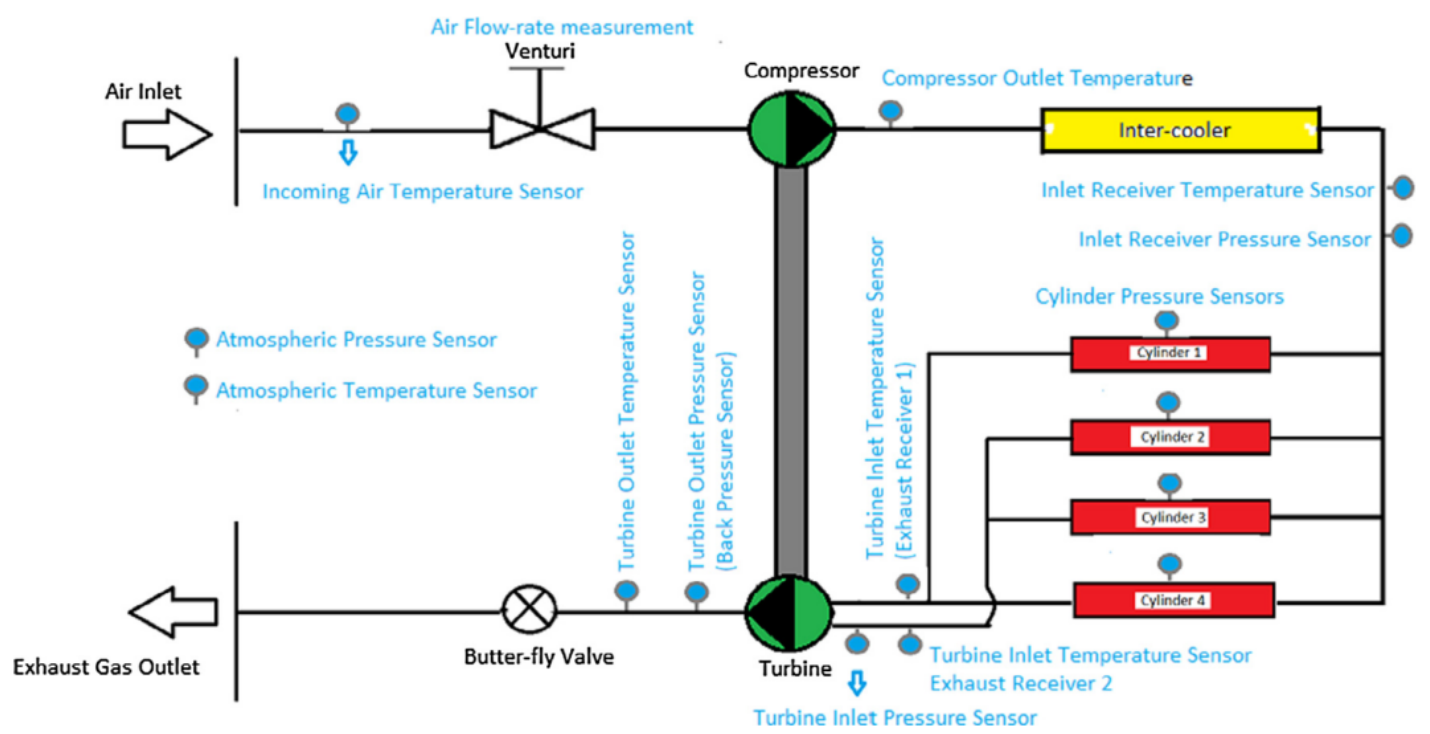

Figure 4: The engine and data collection setup, from Sapra [8]

Based on the (spatially averaged) temperature change in the cylinder and the specific heat of the gas mixture, the net apparent heat release rate (NAHRR) is calculated. Using the formulation proposed by Woshni [10] the heat loss to the cylinder walls, piston and cylinder crown is calculated. Table 2 gives the parameters and temperatures used, as proposed by Ding [4].

Table 2: Heat loss model parameters and temperatures

\begin{tabular}{lcc}
\hline name & value & unit \\
\hline $\mathrm{C} 1$ & 130 & \\
$\mathrm{C} 3$ & $2.28+0.308 \cdot \frac{w_{t}}{c_{m}}$ & \\
$\mathrm{C} 4$ & 0.00324 & {$\left[\mathrm{~m}(\mathrm{sK})^{-1}\right]$} \\
$\mathrm{T}_{\text {wall }}$ & 400 & {$[\mathrm{~K}]$} \\
$\mathrm{T}_{\text {piston }}$ & 600 & {$[\mathrm{~K}]$} \\
$\mathrm{T}_{\text {cyl.h. }}$ & 580 & {$[\mathrm{~K}]$} \\
$\mathrm{T}_{\text {fuel, inj. }}$ & 313 & {$[\mathrm{~K}]$} \\
\hline
\end{tabular}


From the NAHRR and the heat loss calculation the gross apparent heat release rate (GAHRR) can be calculated.

\section{Results}

The fuel properties of F-76 and GTL are presented in Table 3 . GTL has an 8\% lower density, but a 3.5\% higher caloric value than F-76. Sulfur content in GTL is significantly lower compared to F-76.

Table 3: Fuel properties F-76 and GTL

\begin{tabular}{llll}
\hline & F-76 & GTL & unit \\
\hline Density & 847.4 & 779.2 & {$\left[\mathrm{~kg} \mathrm{~m}^{-3}\right]$} \\
Lower heating value & 42.58 & 44.06 & {$\left[\mathrm{MJ}(\mathrm{kg})^{-1}\right]$} \\
Carbon content & 86.6 & 84.4 & {$\left[\%_{m}\right]$} \\
Hydrogen content & 13.1 & 15.0 & {$\left[\%_{m}\right]$} \\
Sulfur content & 0.05 & $<0.01$ & {$\left[\%_{m}\right]$} \\
Cetane number & 45.1 & 74.9 & {$[-]$} \\
\hline
\end{tabular}

Comparing the measured pressure signals shows a lower maximum pressure for GTL, as can be seen in Figure 5 The lower peak pressure results in a slightly lower mechanical load on the piston and cylinder.
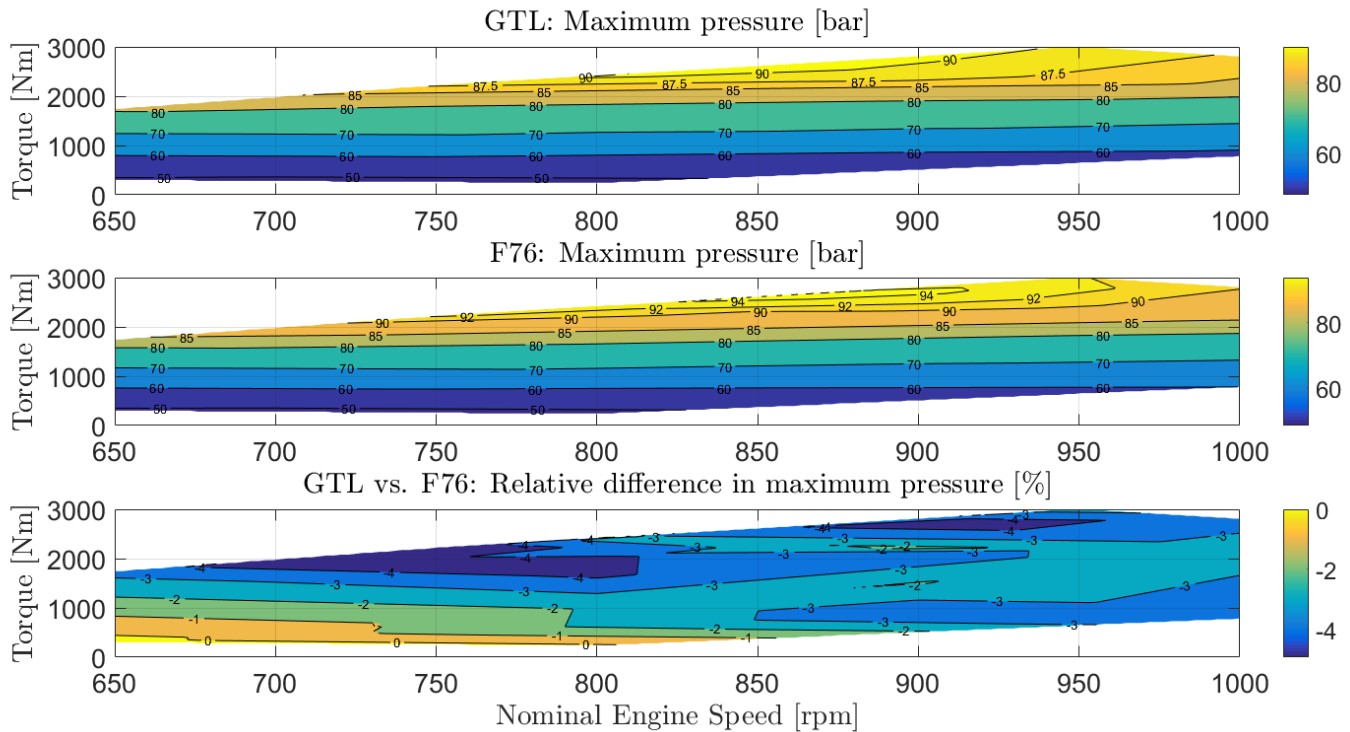

Figure 5: Measured maximum in-cylinder pressure for GTL and F-76, and the relative difference 


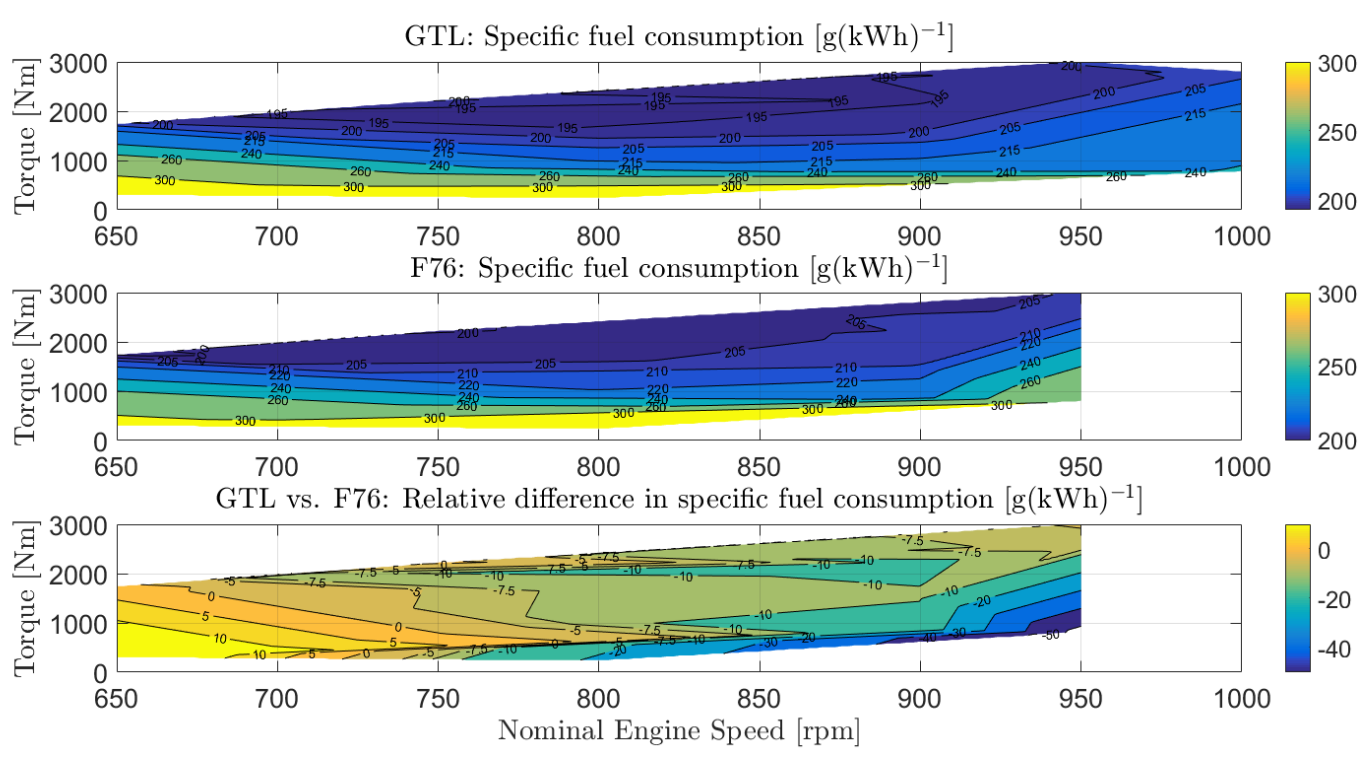

Figure 6: Measured specific fuel consumption for GTL and F-76, and the relative difference

The specific fuel consumption of the engine is expected to be lower for GTL, since the lower heating value (LHV) is higher. Specific fuel consumption is presented in Figure 6 and lowest near the MCR line.

Given the difference in LHV, comparison is better done on an energy basis. Figure 7 shows the overall engine efficiency (brake horse power to energy contained in the injected fuel). The increase in efficiency of up to $0.5 \%$ can come from a combination of four effects. Combustion efficiency is claimed by the manufactorer to be higher for GTL. The indicated efficiency increases, either by a different heat release rate or by reduced heat loss. Finally, the mechanical efficiency can be affected by difference in in-cylinder pressure.

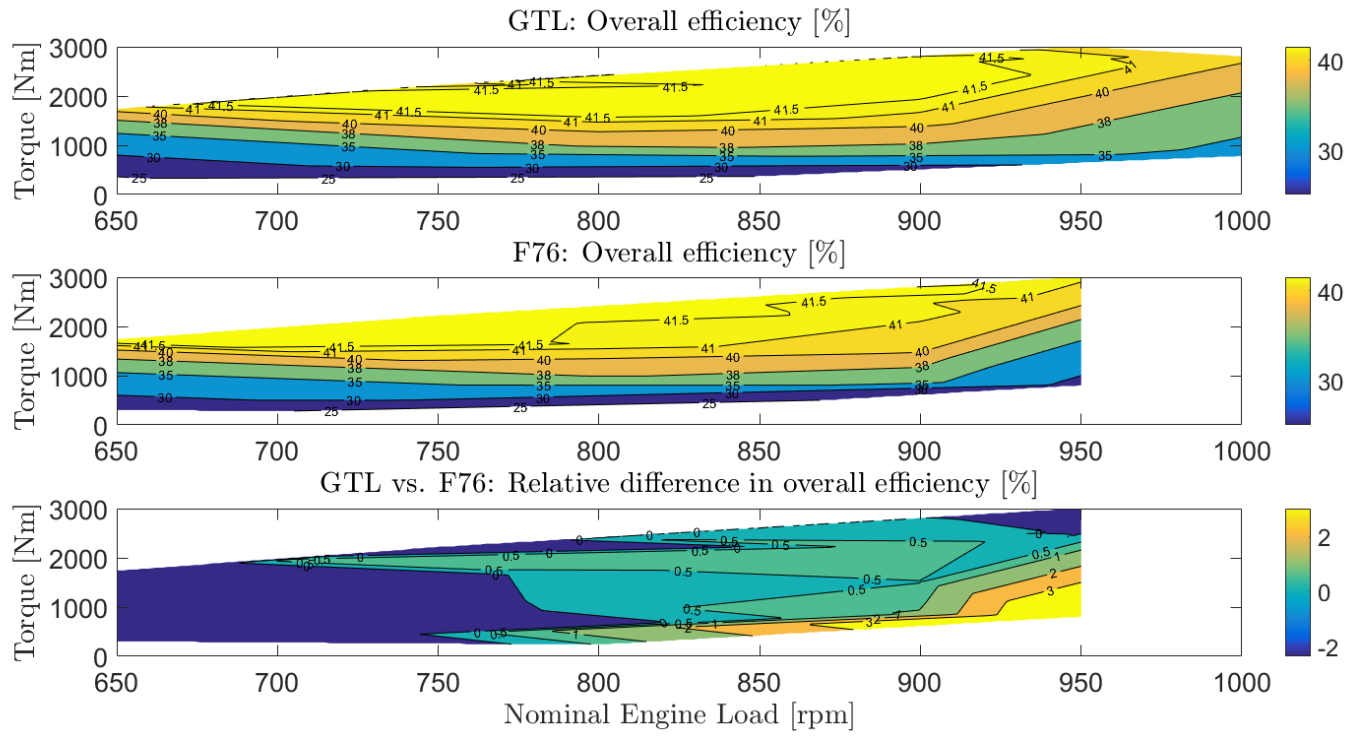

Figure 7: Measured overall efficiency for GTL and F-76, and the difference

Looking at the rate of combustion, two observations can be made. Firstly, combustion starts earlier for GTL as can be seen in Figure 8, which is expected based on the higher cetane number. Secondly, as shown in Figure 9 , combustion duration is longer for GTL. 

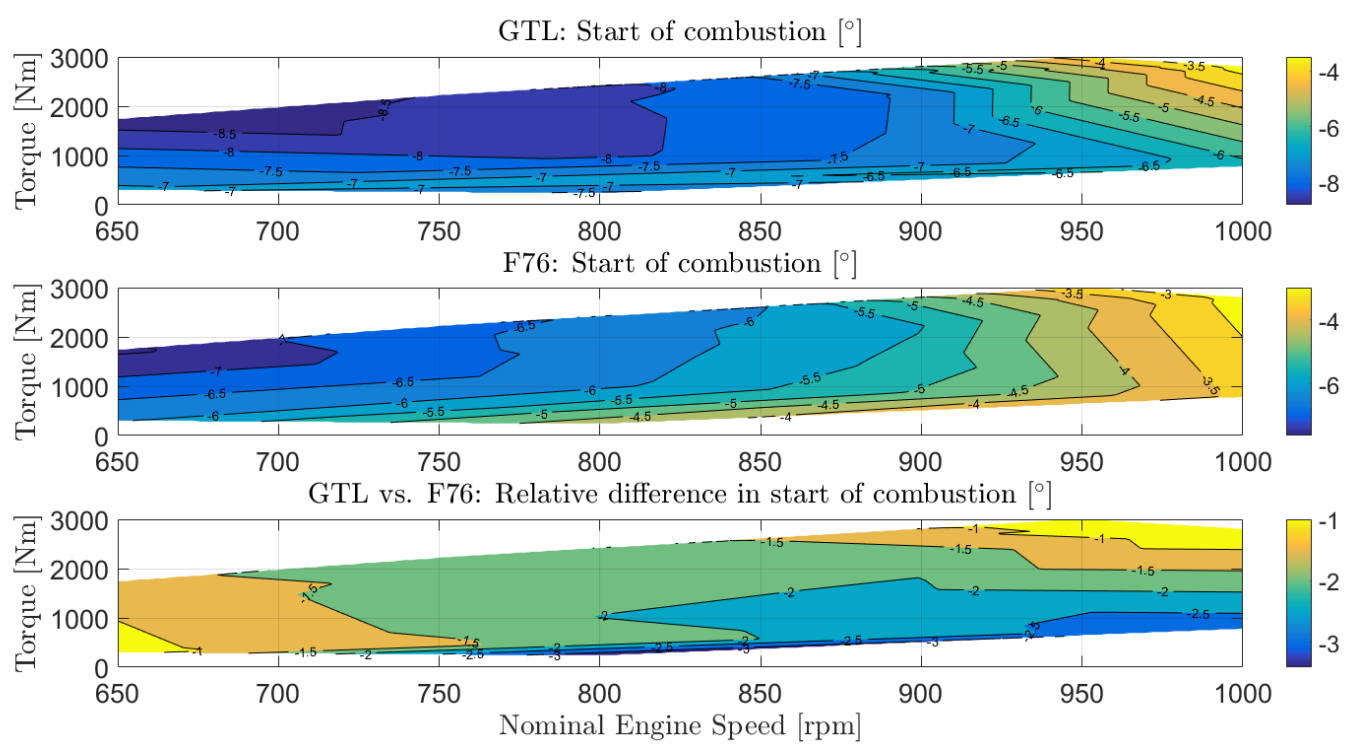

Figure 8: Start of combustion for GTL and F-76, and the relative difference

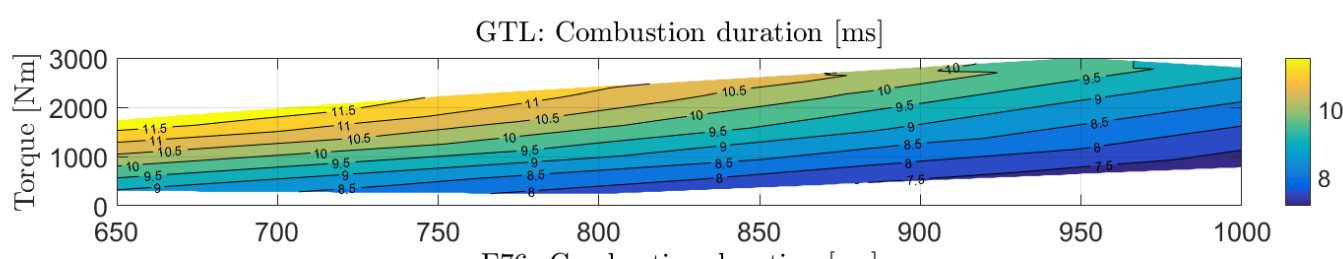

F76: Combustion duration $[\mathrm{ms}]$

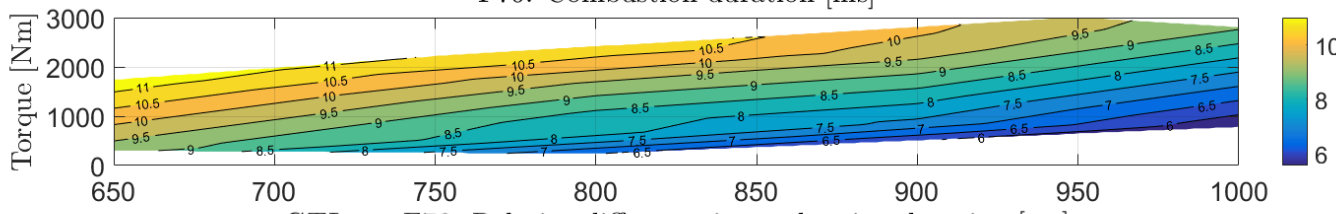

GTL vs. F76: Relative difference in combustion duration [ms]

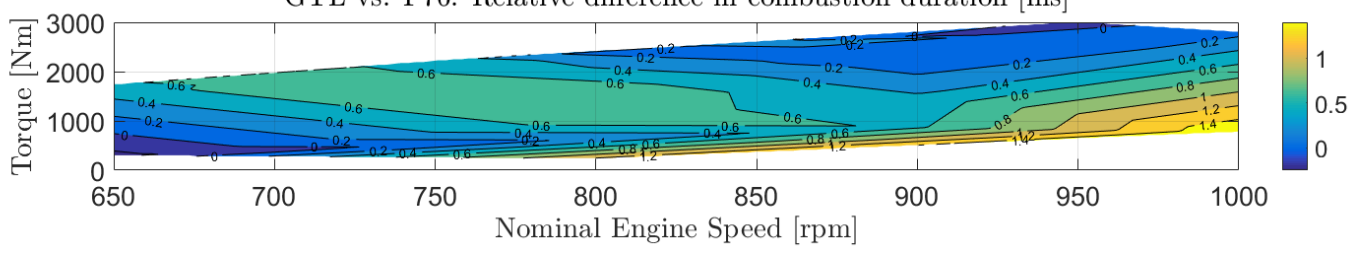

Figure 9: Combustion duration for GTL and F-76, and the relative difference

The NAHRR in figure 10 shows GTL has less premixed combustion compared to F-76. The heat release is more gradual over time/crank-angle. 


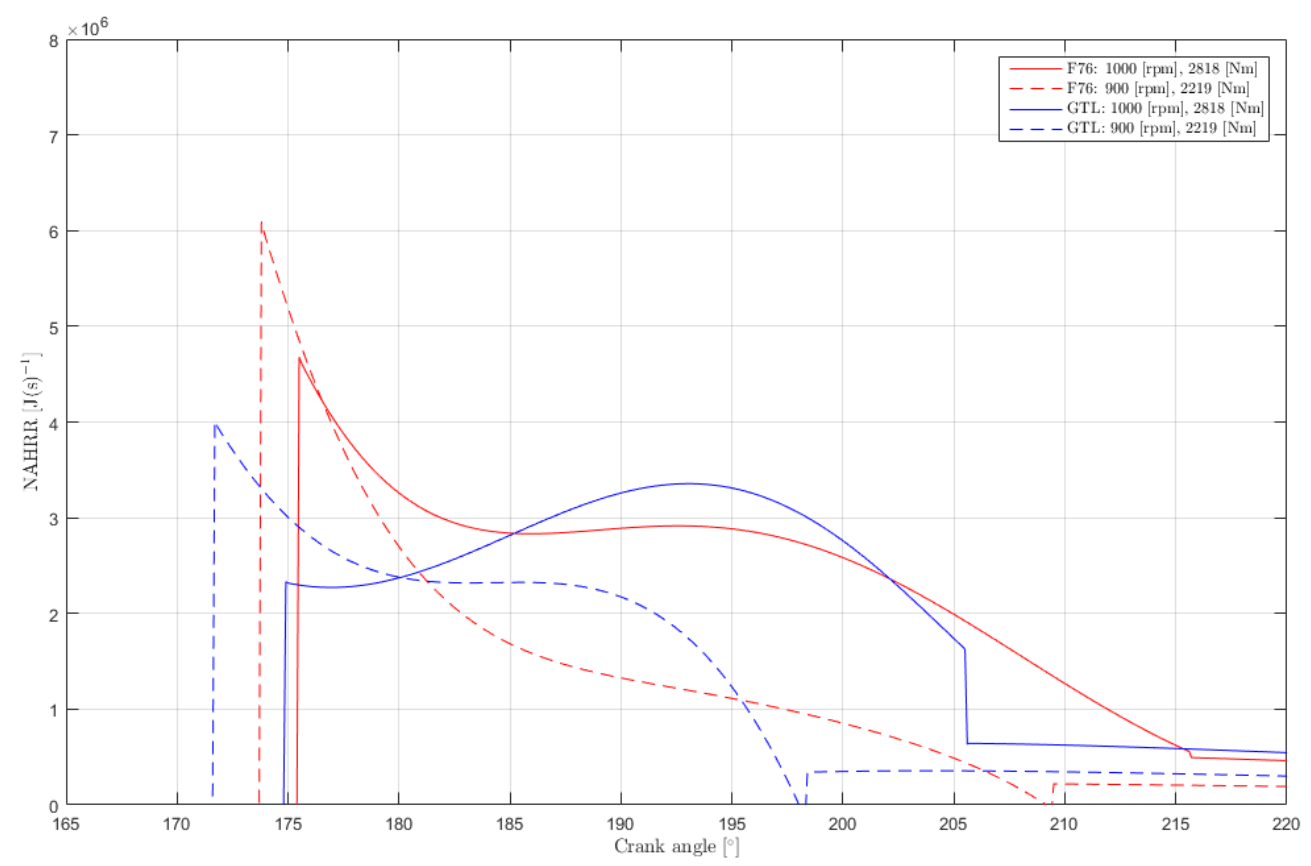

Figure 10: NAHRR of F76 and GTL at 1000 and 900 RPM

The heat loss calculated using the Woshni formulation shows comparable results for GTL and F-76. Therefore, the GAHRR for GTL is also more gradual for GTL than for F-76. The more gradual heat release results in a lower calculated maximum temperature. Since calculations are done using a single-zone model, only a spatially averaged temperature is calculated. Emission measurements show a significant decrease in $N O_{X}$ emission over $9 \%$ for GTL, as can be seen in Figures 11 and 12 . This indicates smaller regions of (extremely) high temperature and/or lower maximum temperature. Therefore, using GTL is likely to reduce thermal loading of the engine.

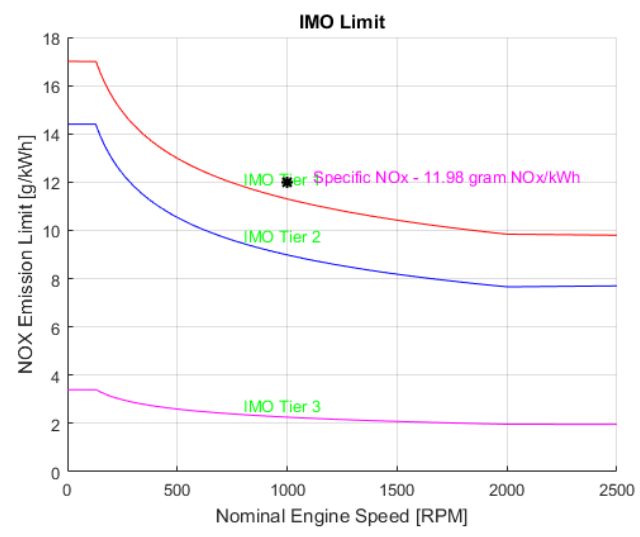

Figure 11: Specific $N O_{X}$ emissions for GTL

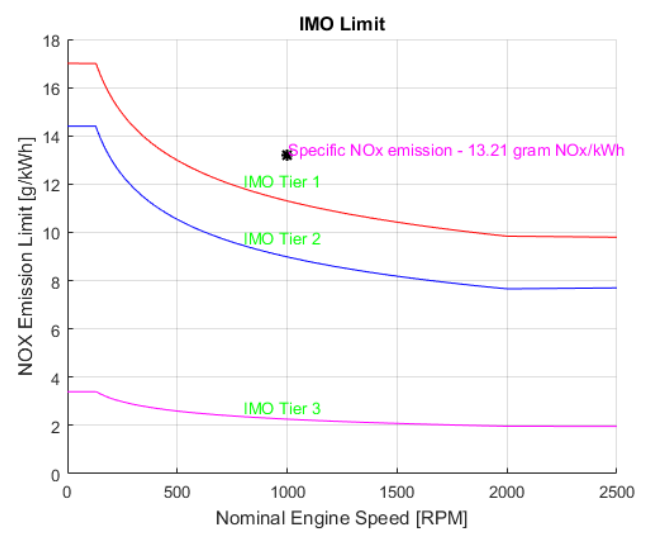

Figure 12: Specific $N O_{X}$ emissions for F-76

\section{Conclusions and further research}

Measurements on a 360kW marine diesel engine showed the heat release of GTL starts earlier and shows less premixed combustion compared to F-76. Therefore, maximum pressure and (spatially averaged) temperature are lower for GTL, resulting in a lower mechanical and thermal loading of the engine. The latter supported by a significant decrease in $N O_{X}$ emission for GTL, indicating smaller regions of (extremely) high temperature and/or lower maximum temperature. A combination of increased combustion efficiency and indicated efficiency results in an increased overall efficiency up to $0.5 \%$. The effect on heat loss and mechanical efficiency is small. 
The significant reduction of $N O_{X}$ emissions over $9 \%$ is an advantage of GTL. Combined with the lower sulfur content, fuel emission regulations are more easily met using GTL than F-76. The downside of GTL is the relative low density compared to F-76. Even when the higher LHV and increased engine efficiency are taken into account, the overall range of the ship would reduce by approximately $4 \%$.

The use of bio-based GTL can help reduce the environmental impact of naval combatants. As most other bio-based liquid fuels, the energy density of the fuel on a volume base is less compared to F-76. For future naval ship designs it is advisable to take operating with lower density fuels into account. Although a reduction in $N O_{X}$ emissions can be accomplished with bio-based fuels, IMO Tier III regulations can hardly be met without aftertreatment or EGR. Finally, cost of alternative fuels to F-76 are generally (much) higher. Although the Department of Defence has no profit objective, budget restrictions are in place and completely switching to bio-based fuels will have financial consequences.

\section{References}

[1] M. A. Bassiony, A. Ibrahim, and M. M. El-Kassaby. An experimental study on the effect of using gas-to-liquid (GTL) fuel on diesel engine performance and emissions. Alexandria Engineering Journal, 55(3):2115-2124, 2016.

[2] J. Bouwmeester. De effecten van Hydrotreated Vegetable Oil (HVO) op dieselmotoren van de marine. 2017.

[3] W. de Jong and J. R. van Ommen. Biomass as a sustainable energy source for the future : fundamentals of conversion processes. 2015.

[4] Y. Ding. Characterising Combustion in Diesel Engines. 2011.

[5] R. Geertsma, R. Negenborn, K. Visser, M. Loonstijn, and J. Hopman. Pitch control for ships with diesel mechanical and hybrid propulsion: Modelling, validation and performance quantification. Applied Energy, 206:1609-1631, nov 2017.

[6] S. G. López. Three-Zone in-cylinder process model for DI diesel engines Sebastián Galindo López. 2014.

[7] MARPOL. International Convention for the Prevention of Pollution from Ships Annex VI, consolidated edition. 2015.

[8] H. Sapra, M. Godjevac, K. Visser, D. Stapersma, and C. Dijkstra. Experimental and simulation-based investigations of marine diesel engine performance against static back pressure. Applied Energy, 204:78-92, 2017.

[9] S. Ushakov, N. G. Halvorsen, H. Valland, D. H. Williksen, and V. Æsøy. Emission characteristics of GTL fuel as an alternative to conventional marine gas oil. Transportation Research Part D: Transport and Environment, 18(1):31-38, 2013.

[10] G. Woschni. A Universally Applicable Equation for the Instantaneous Heat Transfer Coefficient in the Internal Combustion Engine. Technical report: 670931, 76:19, 1967.

[11] K. A. Zinner. Aufladung von Verbrennungsmotoren. Springer Berlin Heidelberg, Berlin, Heidelberg, 1985. 